\title{
ELECTROCARDIOGRAPHIC CHANGES IN CHRONIC COR PULMONALE
}

\author{
BY \\ J. A. KILPATRICK \\ From the Department of Medicine, The University of Sheffield, and the Royal and City General Hospitals, Sheffield \\ Received September 21, 1950
}

Electrocardiographic abnormalities have long been noted in cases of heart failure due to chronic cor pulmonale but there has been much discussion about their diagnostic importance and their causation. This paper is a study of a small series of cases of well established chronic cor pulmonale with congestive heart failure, in an attempt to determine the typical cardiographic pattern and to distinguish, if possible, changes due to abnormality of the heart from changes due to its altered position in the thorax.

History. Einthoven in 1906 noted that deep S waves in lead I and tall R waves in lead III may accompany hypertrophy of the right ventricle. He also noted that changes in the position of the heart in relation to the chest would alter the electrocardiographic appearances. Hermann and Wilson (1922) and Cohn and Raisbeck (1922) made extensive studies of the effect of the position of the heart and of the changes in ventricular hypertrophy, and Lewis (1925) agreed with their conclusions that both rotation of the heart and lesions of conduction might produce the appearance of ventricular preponderance in the cardiogram. Barnes and Whitten (1929) noted depression of the $\mathrm{S}-\mathrm{T}$ segment and inversion of $\mathrm{T}$ waves in leads II and III which they stated accompanied right axis deviation in the typical tracing in cases of right ventricular hypertrophy. Wood and Selzer (1939) used pectoral as well as limb leads in the study of right ventricular hypertrophy and reported among their findings those of six cases of chronic cor pulmonale and five cases of acute cor pulmonale due to pulmonary embolism.

Since the introduction of unipolar lead electrocardiography by Wilson and his colleagues (Wilson et al., 1944; Goldberger, 1949) much more information has been gained about the effects of alterations in the position of the heart, and it is often possible to separate the effects of ventricular hypertrophy from those of positional changes. In chronic cor pulmonale, however, the heart is often rather vertical with clockwise rotation, due presumably to the emphysema which is often the underlying chest condition. The cardiographic result of the change in position is often a tracing resembling that commonly accepted as being due to right ventricular hypertrophy, namely, marked right axis deviation with, in some cases, depression of S-T and inversion of T in leads II and III (Barnes and Whitten, 1929). Identical tracings have, however, been noted to occur in the absence of right ventricular hypertrophy (Myers et al., 1948). Hence it is of the greatest importance in cases where emphysema is associated with heart failure to identify any cardiographic changes that will indicate right ventricular hypertrophy or any other functional change in the right ventricle or auricle in the presence of the pattern of the vertical clockwise-rotated heart.

\section{METHOD}

The electrocardiographic data of 20 cases of well established chronic cor pulmonale diagnosed clinically were studied in detail. The criteria of diagnosis were as follows: in all, there was on admission gross peripheral œdema, raised jugular venous pressure, hepatomegaly, and gross cyanosis. 
There was in all, a long-standing history of chronic cough and breathlessness, and no case was included where there was hypertension or a history of rheumatic fever or signs of rheumatic heart disease such as mitral or aortic diastolic murmurs or an aortic systolic murmur or possible congenital heart disease.

In many cases, on admission a severe broncho-pneumonia complicated the primary chest condition. Four of the patients have died since the investigation started, and in the three where postmortem examination was obtained it confirmed the diagnosis and showed both the expected primary lung condition and right ventricular hypertrophy and an absence of any other lesion except, in two cases, slight thickening of the left ventricle also.

Electrocardiograms were taken on admission and in many cases were repeated at intervals for many months. The leads routinely recorded were the standard bipolar limb leads I, II and III, unipolar limb leads aVR, aVF, and aVL (Goldberger, 1949) and unipolar chest leads V1 to V6. Later, lead V3R was added to the routine list, being recorded from the right pectoral region in a position equivalent to that of $\mathrm{V} 3$, from the left. In some cases unipolar leads were taken circumferentially around the chest and in some cases simultaneous records were made of leads VR (Wilson), V1 and V6 and of V3R, V1 and V6 using the Elmquist triplex electrocardiograph. The records were all uniformly standardized $(1 \mathrm{mv} .=1 \mathrm{~cm}$.) and a standardization curve was recorded at the time so that adjustments could be made in measurement where necessary.

In many of the cases, records were made of the mean right auricular and right ventricular pressures recorded with a saline manometer after cardiac catheterization.

\section{RESULTS AND DisCUSSION}

The cardiographic findings on admission in the 20 cases studied are summarized in order to give data comparable with those previously published. As the analyses of the authors quoted are not in a comparable form it is necessary to present two separate tables. Table I shows the analysis of the

TABLE I

Diagnostic findings in 20 Cases of Chronic Cor Pulmónale compared with 40 Cases of Right VENTRICULAR HYPERTROPHY (Myers et al., 1948)

\begin{tabular}{|c|c|c|}
\hline $\begin{array}{l}\text { Electrocardiographic criteria on which diagnosis of } \\
\text { right ventricular hypertrophy was made }\end{array}$ & $\begin{array}{l}\text { Series of Myers } \\
\text { et al. (1938) } \\
\text { (percentage in } \\
40 \text { cases) }\end{array}$ & $\begin{array}{l}\text { This series } \\
\text { (percentage in } \\
20 \text { cases) }\end{array}$ \\
\hline 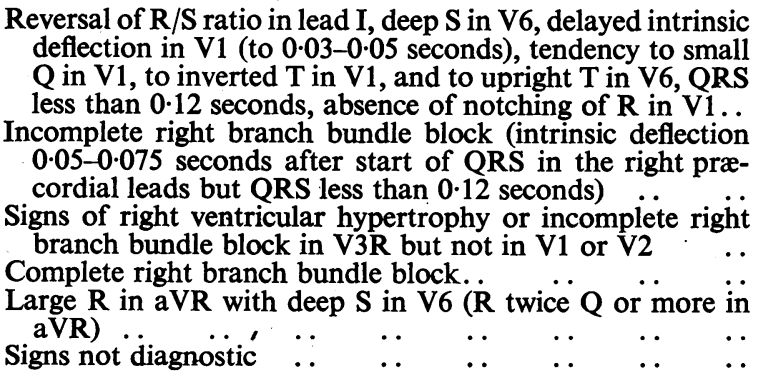 & $\begin{array}{c}32 \cdot 5 \\
\\
22 \cdot 5 \\
5 \cdot 0 \\
7 \cdot 5 \\
15 \cdot 0 \\
17 \cdot 5\end{array}$ & $\begin{array}{c}25 \\
20 \\
10 * \\
0 \\
25 \\
20\end{array}$ \\
\hline
\end{tabular}

* V3R recorded in 11 cases only, two of which showed this finding.

findings by the criteria used by Myers et al. (1938) in the cardiographic diagnosis of right ventricular hypertrophy in 40 cases in which autopsy confirmation was obtained, and a comparable analysis of the present series. Table II shows a comparison of the incidence of cardiographic signs in these 20 cases with that given by Wood (1948) in his series of 100 cases of chronic cor pulmonale. 
TABLE II

Electrocardiographic Signs in 20 Cases of Chronic Cor Pulmonale compared with the Findings OF WOOD (1948) IN 100 CASES

\begin{tabular}{|c|c|c|c|}
\hline \multicolumn{2}{|c|}{ Electrocardiographic signs in chronic cor pulmonale } & $\begin{array}{c}\text { Series of Wood } \\
\text { (1948) } \\
\text { (percentage in }\end{array}$ & $\begin{array}{l}\text { This series } \\
\text { (percentage in }\end{array}$ \\
\hline 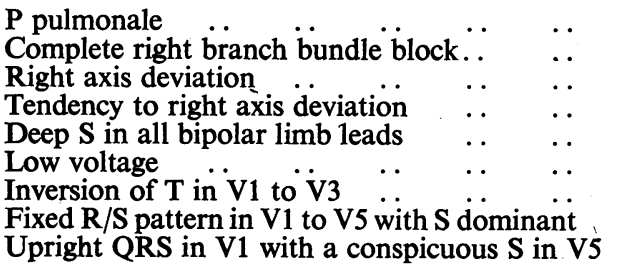 & $\begin{array}{ll}\cdots & \cdots \\
\therefore & \cdots \\
\cdots & \cdots \\
\cdots & \cdots \\
\cdots & \cdots \\
\cdots & \cdots \\
\cdots & \cdots\end{array}$ & $\begin{array}{r}85 \\
4 \\
46 \\
11 \\
9 \\
40 \\
13 \\
16 \\
16\end{array}$ & $\begin{array}{l}60 \\
0 \\
85^{*} \\
5 \\
20 \\
15 \\
85 \\
40 \\
25\end{array}$ \\
\hline
\end{tabular}

* In 30 per cent there was marked right axis deviation with depression of S-T and inversion of $\mathrm{T}$ in II and III.

It will be noted that 60 per cent of the cases showed the $P$ pulmonale, a sharply peaked $P$ wave of $2.5 \mathrm{~mm}$. or more in height in the standard leads or of $3 \mathrm{~mm}$. or more in the chest leads, and that this finding compares with that of Wood in being most significant. Myers et al. (1948) and Zuckermann et al. (1948) postulated that this tall $P$ wave could be natural when there was a low vertical heart, but Wood (1948) stated that it was never seen in normal vertical hearts.

Inversion of $\mathrm{T}$ in V1, V2, and V3 was present in 85 per cent, whereas this sign was not prominent in the cases described by Wood (1948). The frequency of this finding may have been related to the advanced nature of the cases selected for study. Nearly all showed right axis deviation and 30 per cent showed the pattern described by Barnes and Whitten (1929), with depression of S-T and inversion of T II and T III.

The pattern described by Myers and his colleagues (1948) consisting of reversal of the R/S ratio in V1, a deep $\mathrm{S}$ in V6, delay of the intrinsic deflection in V1 to 0.03-0.05 sec., with a tendency to a small $Q$ in V1, to inversion of $T$ in V1, and an upright $T$ in V6, but with a total QRS time less than $0 \cdot 12$ sec. and without notching of $\mathrm{R}$ in $\mathrm{V} 1$, was seen in 25 per cent of the cases, a figure comparable to that given by Myers. Fig. 1 shows an example of this type of tracing. Wood (1948) stated that 16 per cent of his cases showed a chiefly upright QRS in V1 with a conspicuous S wave in V6. Complete right branch bundle block was not seen in any of the tracings taken on admission but developed some three months later in one patient. Incomplete right branch bundle block (delay of the intrinsic deflection of V1 or V3R to $0.05-0.075 \mathrm{sec}$. with a total QRS time of $0.12 \mathrm{sec}$. or less) had not previously been observed in this patient. Incomplete right branch bundle block was noted in the right præcordial leads in four $(20 \%)$ of the cases, and Fig. 2 shows such a tracing. Incomplete right branch bundle block was seen in V3R in one patient when it was not present in V1 or V2 and conduction delay was present in one other case in V3R but not in V1 or V2 (delay of the intrinsic deflection to 0.03-0.05 sec., Myers et al., 1948, and Wilson et al., 1947). If V3R had been recorded in the earlier cases it is likely that some at least would have shown abnormal conduction here.

There was a significant late $R$ wave in aVR in all the 20 cases. In 25 per cent, $R$ in aVR was at least twice the size of $\mathrm{S}$ and there was a deep $\mathrm{S}$ wave in V5. This had been a diagnostic feature in 15 per cent of the cases of Myers et al. (1948). The QR pattern in aVR is described by Goldberger (1949), who considered that it occurred in marked clockwise rotation of the heart with backward rotation of the apex, the tall $R$ wave being a reflection of the termination of the spread of the impulse through the epicardial portion of the left ventricular wall at the back of the heart. He noted also that a very tall $R$ wave in aVR (more than twice the size of the $Q$ wave) might occur in right ventricular hypertrophy. Myers et al. (1948) gave considerable attention to the presence of the R wave 


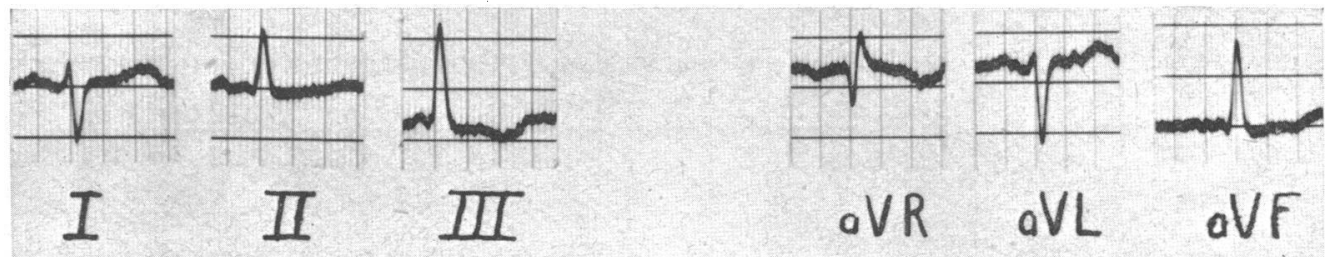

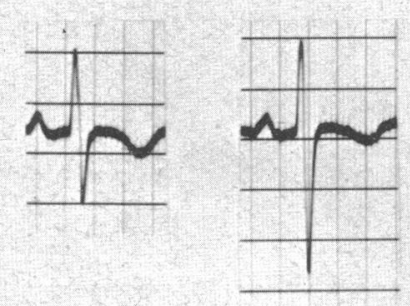

$V_{1}$

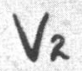

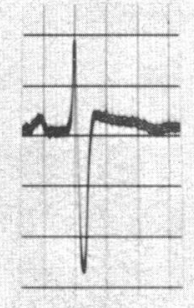

$V_{3}$

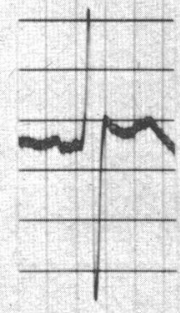

$V_{k}$

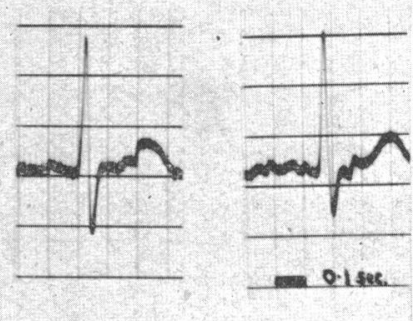

$V_{5}$ $\underline{\underline{w}}$

I

$\stackrel{2}{\frac{2}{7}}$

c.

$\overrightarrow{\bar{F}}$

음

$\frac{0}{\overparen{D}}$

$\overrightarrow{0}$

$\vec{\omega}$

م

$\stackrel{?}{\vec{I}}$

$\dot{\omega}$

ట్

옥

产

FIG. 1.-Electrocardiogram in a case of chronic cor pulmonale showing the large $\mathbf{R}$ wave in the right-sided chest leads and in $\mathrm{VVR}$, a significant $\mathrm{S}$ in V6, and inversion of $\mathrm{T}$ in all the chest leads to the right of V4.
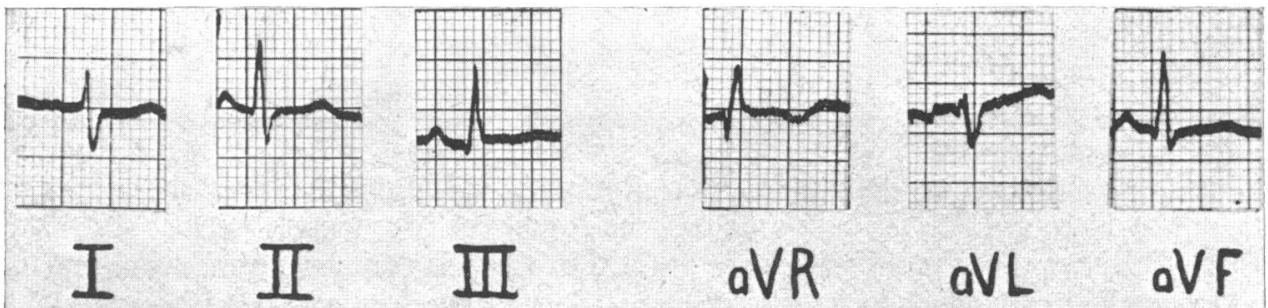

$a V R$
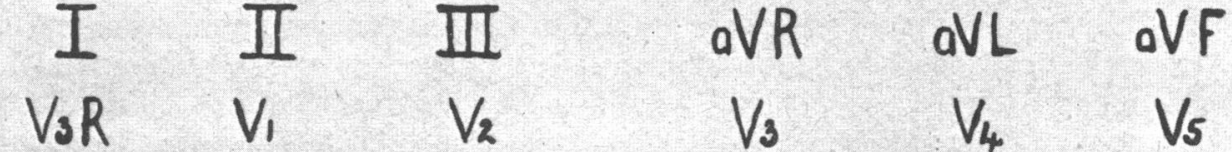

$V_{2}$
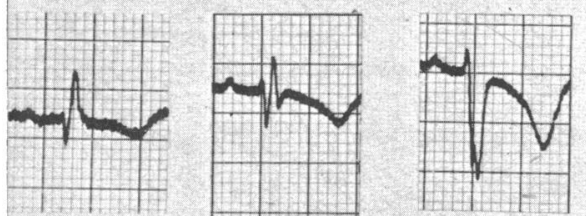

$V_{4}$

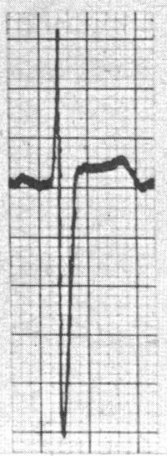

FIG. 2.-Electrocardiogram in a case of chronic cor pulmonale showing incomplete right branch bundle block, the large late $R$ in aVR, V3R, and V1, a significant S in V5, and inversion of $T$ in the chest leads to the right of V4. 
in aVR in right ventricular hypertrophy but agreed with Goldberger that this wave was produced by the left ventricle and was due to the rotation of the heart. Schlesinger et al. (1949) showed by intracardiac and œsophageal leads that aVR showed an $\mathrm{R}$ wave in right ventricular hypertrophy which they suggested was probably due to late activation of the right ventricular wall and the observations of Sodi-Pallares et al. (1947) seem to agree with this concept. Hecht (1946) had shown by intracardiac leads that in right branch bundle block VR resembled the high intra-auricular leads and might show a small $Q$ and a large slow $R$, as the cavity potential in right branch bundle block was at first negative on the left, then finally positive on the right.

In the 20 cases observed, the $R$ wave in aVR was relatively small in two only (1/4 of the $Q$ wave), but in most the $R$ wave was the striking feature, being usually twice or three times larger than the $Q$ wave and in two cases five and six times the size.

The position of the heart was analysed by the criteria of Goldberger (1949). In only one case was there a horizontal heart and this was associated with marked clockwise rotation and forward rotation of the apex; here the $R$ wave was only half the size of the $Q$ wave in aVR. In 19 cases the heart was vertical, in six with moderate and in 13 with marked clockwise rotation (moderate when R equalled $S$ in size in V4 or V5 and marked when the transition point lay beyond V5). The $R$ wave in aVR tended to be higher when marked clockwise rotation was present. There was, however, no correlation between the height of the $R$ wave in aVR and the presence or absence of backward rotation of the apex which was almost evenly distributed among the 19 vertical hearts and there was no correlation between the presence or absence of $P$ pulmonale and the height of $\mathrm{R}$ in aVR.

In order to determine the source of the large $\mathrm{R}$ wave in the right arm lead records were made of VR, V1, and V6 simultaneously, and also of V3R, V1, and V6 simultaneously in nine cases, and in six of these multiple leads were taken circumferentially around the chest. Where V3R showed an $R$ wave this $R$ wave was synchronous with the $R$ of VR. In all nine cases examined the $R$ of $V R$ and of V3R was synchronous with the R of V1 and occurred much later than the R of V6. Fig. 3

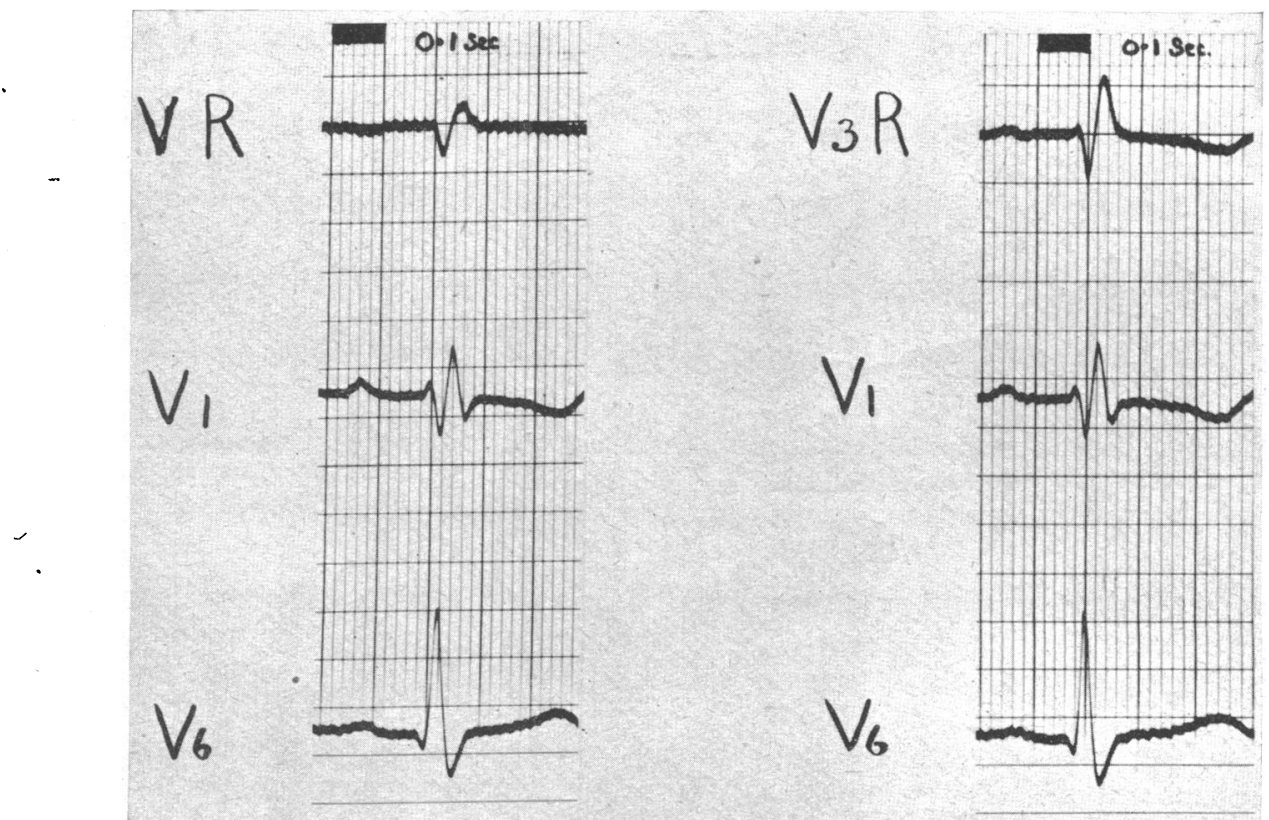

FIG. 3.-Electrocardiogram in a case of chronic cor pulmonale showing simultaneous records of VR, V1, and V6; and of V3R, V1, and V6. $R$ in VR and V3R corresponds to $R$ in V1, but is significantly later than $R$ in V6. 
shows the type of tracing obtained. In the six cases in which circumferential chest leads were available five showed that the $R$ wave in aVR was unlikely to be a reflection of left ventricular excitation because the $\mathrm{R}$ wave of V6 became progressively smaller when the exploring electrode moved to the left and was almost absent over the spine or in the right posterior chest leads while there was still an appreciable $\mathrm{R}$ in the anterior right chest leads and in lead aVR. Fig. 4 illustrates this finding diagrammatically. In the remaining case the left ventricular $R$ wave persisted in the posterior chest leads and merged with the $R$ wave from the anterior right chest. Here the $R$ in VR was only slightly delayed in time from the R of V6 so that the R in VR may have had a composite origin, both from

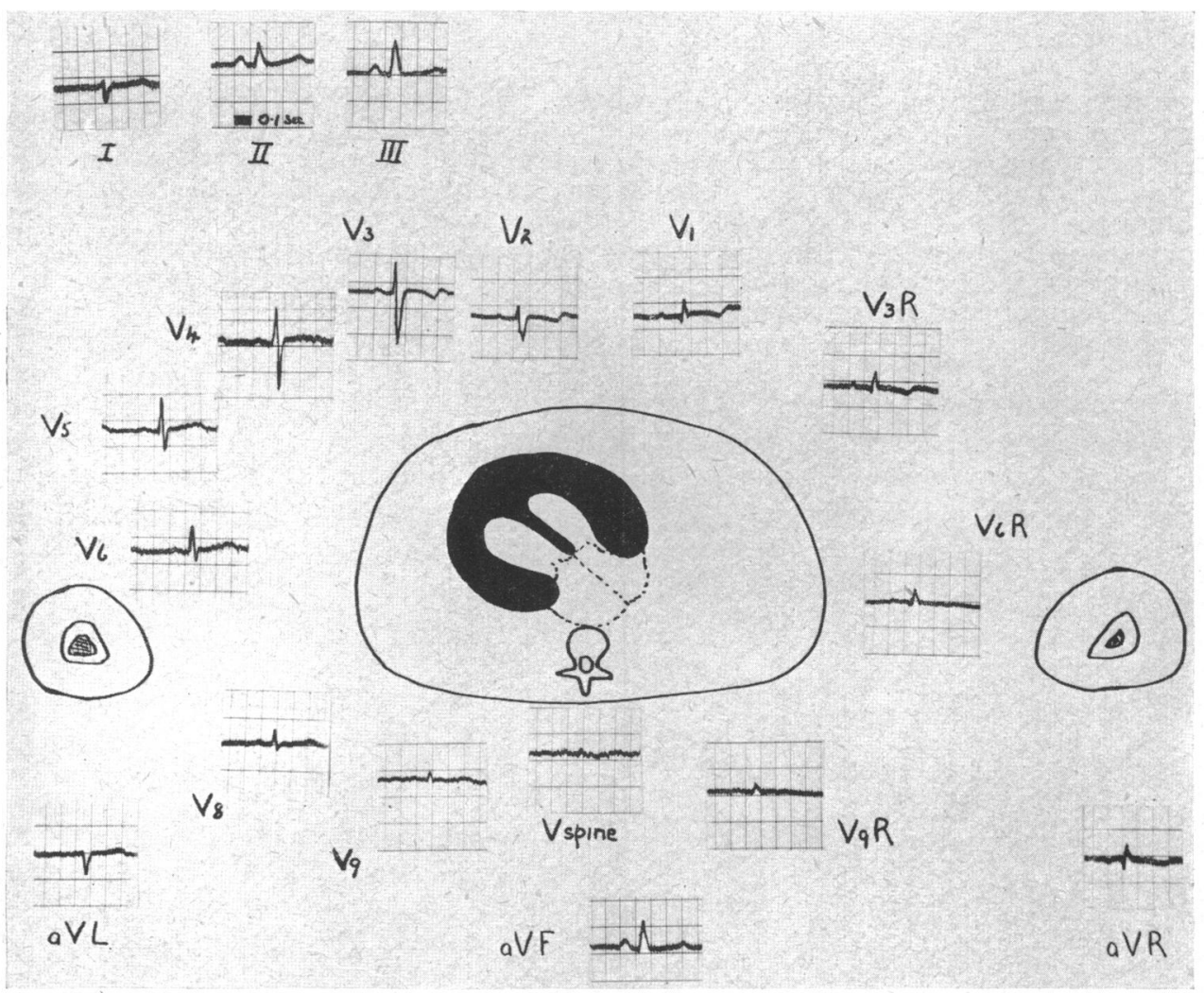

Fig. 4.-Electrocardiogram in a case of chronic cor pulmonale showing diagrammatically a horizontal cross-section of chest and arms at about the fourth costal cartilage. Each unipolar lead tracing is mounted opposite the site of the exploring electrode. Note the delayed R in V1, Y3R, V6R, and aVR, and the absence of the left ventricular $R$ wave in V spine suggesting that the $R$ wave in aVR is related more to right than to left ventricular excitation.

the left and right ventricular walls as is suggested by Myers et al. (1948). The large late $\mathrm{R}$ wave in aVR and in V3R seems likely therefore to be related in most cases of chronic cor pulmonale without complete right branch bundle block to right ventricular excitation, probably to the final spread of the impulse outward through the thickened right ventricular wall.

A cardiographic diagnosis of chronic cor pulmonale could be made in 19 of the 20 cases examined. In 12 there was a well marked $P$ pulmonale, and a further 3 showed the common pattern described by Myers et al. (1948) in right ventricular hypertrophy. One further case showed incomplete branch bundle block in V3R but not in V1 or V2 and one more showed conduction delay in V3R only. In two others there was a large $R$ in aVR and a deep S in V6. In one of these two, V3R also showed a 
large $\mathrm{R}$ but the intrinsic deflection was not delayed and in the other no V3R was available. In the remaining case the tracing was not diagnostic, showing only rather low voltage curves, right axis deviation, a vertical heart with moderate clockwise rotation, and a small $R$ in aVR only half the size of the $Q$ wave; no V3R was taken: this case came to necropsy and showed well marked right ventricular hypertrophy and dilatation, very slight left ventricular hypertrophy, and chronic pulmonary fibrosis due to lipoid pneumonia.

In 13 of the 20 cases serial electrocardiograms are available; none of these 13 had taken any digitalis for at least a month before admission. Nine of the 13 cases showed considerable improvement in the pattern coincident with improvement in the clinical condition. The changes noted included improvement in the $\mathrm{P}$ wave in 5 and decrease in the extent of $\mathrm{T}$ wave inversion in the chest leads in 8 cases. The $P$ wave in several cases decreased from a sharply peaked wave of well over $3 \mathrm{~mm}$. in height to a pattern that was not in any way abnormal although in one the typical P pulmonale became converted into a low flat $P$ of $0.12 \mathrm{sec}$. in duration and only $1.5 \mathrm{~mm}$. in height. Improvement in the clinical state was associated in one case, to be described $m$ more detail later, with reversal of the inverted T waves in V1 to V4 to a normal upright pattern in a little over a month, and with loss of the $P$ pulmonale pattern six weeks later. In two of the three cases where the $P$ wave became normal with clinical improvement, no change in the cardiographic position of the heart was seen in later tracings suggesting that the abnormality of the $P$ wave was not due to a positional change of the heart. In two cases inversion of $\mathrm{T}$ in V1 to V4 became reduced to inversion in V1 and $\mathrm{V} 2$ only and in four others inversion of V1, V2, and V3 was converted to an upright pattern in all three leads in from two to six months while in one further case inversion of $T$ in V1, V2, and V3 was reduced to inversion in V1 and V2 only after a period of five months.

All these records were analysed in terms of Goldberger's criteria (1949) for the position of the heart but in 8 of the 9 cases where this striking cardiographic improvement occurred no change in the position of the heart was found. In the case mentioned above, where clinical improvement was associated with a quick return to normal of the inverted T waves in V1 to V4 and a later return to normal of the $P$ wave, the position of the heart remained vertical with backward rotation of the apex but clockwise rotation, which was marked on admission, was only moderate a month later and disappeared in the next month. The extent and rapidity of the clinical recovery in this case was remarkable. Although his history and physical signs were those of chronic cor pulmonale with congestive failure of two months' duration the progress suggested that there had been a super added acute cor pulmonale. The possibility that there had been pulmonary embolism could not be excluded with certainty.

In five cases that showed, on admission, delay in conduction in the right sided chest leads or incomplete right branch bundle block no improvement was shown in conduction in later tracings even though improvement occurred in the inversion of the $T$ waves of the right-sided chest leads in all. In.two further cases incomplete right branch bundle block appeared for the first time in subsequent tracings, and in one of these coincided with the reversal of previously inverted $\mathrm{T}$ waves in V1, V2, and V3. In another complete right branch bundle block developed four months after the original tracing had been taken and while the clinical state remained considerably improved.

These observations suggest that the conduction delay so commonly observed in the right-sided chest leads and the signs of right ventricular hypertrophy have a separate origin from the $T$ wave inversion of these leads. The term " right ventricular strain" has been used by various workers with varying implications (Wilson et al., 1947; Katz, 1946; Katz and Wenstein, 1947; Goldberger, 1949). In view of the reversible nature of the inversion of the $T$ wave in the right-sided chest leads in chronic cor pulmonale and the doubt as to the cause of this pattern it seems that " right ventricular strain " is a term best reserved exclusively to describe this inverted $T$ pattern and this definition will be followed in the following discussion.

Temporary inversion of the $T$ wave in the right-sided chest leads often occurs in acute pulmonary embolism where it is not necessarily associated with right ventricular hypertrophy (Wood and Selzer, 1939). In the cases of chronic cor pulmonale described here there is no reason to suppose that right ventricular hypertrophy has been in any way reduced, yet the inverted $T$ waves became 
upright, suggesting that the pattern of right ventricular strain was not dependent upon right ventricular hypertrophy. A similar conclusion with regard to the inverted T waves of the left-sided chest leads in essential hypertension may be made from the observation by White et al. (1945) that after sympathectomy the appearances of left ventricular strain may disappear in some cases without any decrease in the size of the heart radiologically or in the level of the peripheral blood pressure. Zuckermann et al. (1948) suggested that the right ventricular strain pattern is due to a change in rotation of the heart towards a more juvenile position, but the observations recorded here suggest that it is not necessarily dependent on a change in cardiac position in chronic cor pulmonale. Goldberger (1949) also drew an analogy between right-ventricular strain and the juvenile pattern, but did no more than suggest that the potassium metabolism might be altered in both cases.

Mean right intracardiac pressures measured by saline manometry after cardiac catheterization in 12 cases of chronic cor pulmonale are shown in Table III with an analysis of the cardiographic findings at the time-the observations were made. There was no relation between either auricular or

TABLE III

Electrocardiographic Appearances and Findings in Chronic Cor Pulmonale and levels of Right Auricular and Ventricular Pressure

\begin{tabular}{|c|c|c|c|c|c|c|}
\hline \multirow{3}{*}{ Patient } & - & \multicolumn{2}{|c|}{ Electrocardiographic findings } & & \multirow{2}{*}{\multicolumn{2}{|c|}{$\begin{array}{l}\text { Mean pressures in } \mathrm{cm} \text {. of } \\
\text { saline above sternal angle }\end{array}$}} \\
\hline & \multirow{2}{*}{ P pulmonale } & \multirow{2}{*}{$\begin{array}{c}\text { Right ventricular } \\
\text { strain. Inversion } \\
\text { of } \mathrm{T} \text { in } \\
\mathrm{V} 1-\mathrm{V} 4=+++ \\
\mathrm{V} 1-\mathrm{V} 3=++ \\
\mathrm{V} 1-\mathrm{V} 2=+\end{array}$} & \multirow{2}{*}{$\mid \begin{array}{c}\text { Right bundle branch } \\
\text { conduction delay. } \\
\text { Intrinsic deflection. } \\
\text { V1 or V3R. } \\
0.03-0.05 \text { sec. }=+ \\
0.05-0.075 \text { sec. }=++\end{array}$} & \multirow{2}{*}{$\begin{array}{l}\text { Right ventricular } \\
\text { hypertrophy }\end{array}$} & & \\
\hline & & & & & $\begin{array}{l}\text { Right } \\
\text { atrium }\end{array}$ & $\begin{array}{c}\text { Right } \\
\text { ventricle }\end{array}$ \\
\hline $\begin{array}{l}\text { Bra. } \\
\text { Bo. } \\
\text { Sm. } \\
\text { St. } \\
\text { Sh. } \\
\text { Ro. } \\
\text { Wr. } \\
\text { Ca. } \\
\text { Hudg. } \\
\text { Huds. } \\
\text { Ne. } \\
\text { Bri. }\end{array}$ & $\begin{array}{l}0 \\
0 \\
0 \\
0 \\
0 \\
+ \\
+ \\
0 \\
0 \\
0 \\
+ \\
0\end{array}$ & $\begin{array}{c}++ \\
+++ \\
++ \\
0 \\
0 \\
+++ \\
++ \\
+++ \\
+++ \\
++ \\
0 \\
.\end{array}$ & $\begin{array}{c}0 \\
+ \\
+ \\
+ \\
0 \\
+ \\
0 \\
++ \\
0 \\
0 \\
0 \\
.\end{array}$ & $\begin{array}{l}+ \\
+ \\
+ \\
+ \\
0 \\
+ \\
+ \\
+ \\
+ \\
+ \\
+ \\
\therefore\end{array}$ & $\begin{array}{l}+19.0 \\
+10.0 \\
+14.0 \\
+15.5 \\
+\quad 1.0 \\
+\quad 2.5 \\
-\quad 7.0 \\
+\quad 6.5 \\
+\quad 2.5 \\
+\quad 7.0\end{array}$ & $\begin{array}{c}+48.0 \\
+45.0 \\
+44.5 \\
+39.0 \\
+34.5 \\
+29 \cdot 0 \\
+24.0 \\
+22.0 \\
+20.0 \\
. . \\
. .\end{array}$ \\
\hline
\end{tabular}

$0=$ absent $;-=$ no record made.

ventricular pressure and the presence of the $\mathrm{P}$ pulmonale but as only three of the cases show this feature little can be deduced. Wood (1948) also failed to show any strict proportional relationship between intracardiac pressures and the $P$ pulmonale. Similarly, no strict relationship exists between the degree of strain and the mean ventricular pressure, in fact it is quite striking that the most extensive appearances of strain seem to be associated with pressures little above normal. Conduction delay and incomplete right branch bundle block are similarly associated with pressures in all ranges.

Barber et al. (1950) in their cases of congenital atrial septal defect noted the lack of elevation of the pulmonary arterial and right ventricular pressure, yet right branch bundle block, complete or incomplete, was present in almost all of the cases. The evidence, however, was not sufficient for them to suggest whether this conduction defect was congenital or was associated more with hypertrophy or dilatation of the right ventricle, but they point out that dilatation may produce homolateral branch bundle block experimentally or in pulmonary embolism, and that dilatation is a frequent and early accompaniment of congenital atrial septal defect.

The diagnostic significance of the signs of conduction delay and incomplete right branch bundle 
block are discussed by Wilson et al. (1947) and by Myers et al. (1948). The latter considered that conduction delay of 0.03 to $0.05 \mathrm{sec}$. in the intrinsic deflection after the start of the QRS in the rightsided chest leads was part of the cardiographic picture of right ventricular hypertrophy while incomplete right branch bundle block might be associated with dilatation of the right ventricle or other temporary phenomena. The distinction between these two forms of delayed conduction is not always clear. In one case of incomplete right branch bundle block in the present series there was no notching of $\mathrm{R}$ yet the intrinsic deflection was delayed to $0.06 \mathrm{sec}$. after the start of QRS (in V1, Fig. 2). None of the cases showing right-sided conduction delay or incomplete right branch bundle block developed any change in the pattern when observed over many months. It seems possible that incomplete right branch bundle block in cases of chronic cor pulmonale is often a further stage of the conduction delay associated with hypertrophy, while the pattern of right ventricular strain has a rather different origin associated perhaps with dilatation of the right ventricle.

\section{SUMMARY AND CONCLUSIONS}

An analysis of the electrocardiographic data of 20 cases of well established clinical cor pulmonale with congestive heart failure is presented and shows that multiple unipolar lead electrocardiography is most useful in confirming the diagnosis.

The presence of the $P$ pulmonale, a tall peaked $P$ wave $2.5 \mathrm{~mm}$. or more in height in the limb leads or $3.0 \mathrm{~mm}$. or more in the chest leads, is a most useful sign that does not appear to be related to the position of the heart in the thorax. This sign disappeared as the clinical state improved in two cases without any change in the cardiographic position of the heart.

The derivation and significance of the $R$ wave in lead aVR is studied using multiple unipolar chest and limb leads. It is concluded that the late $R$ wave in aVR and in V3R is often related to right ventricular excitation in chronic cor pulmonale. Right ventricular hypertrophy may be suspected when leads $a V R$ and V3R show a late $R$ wave even in the presence of a vertical heart with clockwise rotation, but only when complete right branch bundle block is absent.

Conduction delay in V3R, V1, or V2 when absent in V5 and-V6 is useful confirmatory evidence of right ventricular hypertrophy. Conduction delay is defined as delay of the intrinsic deflection to between 0.03 and $0.05 \mathrm{sec}$. after the start of the QRS when QRS measures $0.12 \mathrm{sec}$. or less.

Incomplete right branch bundle block, defined as delay of the intrinsic deflection in V3R, V1, or V2 to between 0.05 and $0.075 \mathrm{sec}$. after the start of a QRS wave which is not over $0.12 \mathrm{sec}$. in duration, and where the intrinsic deflection in V5 and V6 is not delayed, is discussed and is suggested also to be associated with right ventricular hypertrophy.

Right ventricular strain, defined as the appearance of inversion of the $\mathrm{T}$ wave in all the rightsided chest leads across to V2, V3, or V4 is not necessarily due to right ventricular hypertrophy, but is often associated with acute phases in the course of chronic cor pulmonale and may disappear as the clinical condition improves. It is suggested that this pattern may accompany right ventricular dilatation.

Intracardiac pressures recorded after cardiac catheterization in 12 cases of chronic cor pulmonale are presented. There was no direct relationship between the degree of cardiographic right ventricular strain and the level of mean right ventricular pressure. Similarly, right-sided conduction delay and incomplete right branch bundle block were not directly related to the degree of elevation of right ventricular pressure.

The author wishes to thank Professor C. H. Stuart-Harris, Department of Medicine, University of Sheffield, for his help and encouragement and for access to the cases in his wards, and also Professor E. J. Wayne of the Department of Pharmacology and Therapeutics, University of Sheffield, for his advice and criticism during the progress of the investigation, and Dr. C. E. Davies, Department of Medicine, University of Sheffield, for permission to use the results of cardiac catheterizations undertaken jointly. Thanks are also due to Mr. A. B. Kesteven, who recorded most of the electrocardiograms used in the investigation. 


\section{REFERENCES}

Barber, J. M., Magidson, O., and Wood, P. (1950). Brit. Heart J., 12, 277.

Barnes, A. R., and Whitten, M. B. (1929). Ibid., 5, 14.

Cohn, A. E., and Raisbeck, M. J. (1921-2). Heart, 9, 311

Einthoven, W. (1906). Arch. Internat. Physiol., 4, 132.

Goldberger, E. (1949). Unipolar Lead Electrocardiography. 2nd ed., London, Henry Kimpton.

Hecht, H. A. (1946). Amer. Heart J., 32, 39.

Hermann, G. R., and Wilson, F. N. (1921-2). Heart, 9, 91.

Katz, L. N. (1946). Electrocardiography. 2nd ed., London, Henry Kimpton. and Weinstein, W. (1947). Med. Clin. N. Amer., 31, 172.

Lewis, T. (1925). The Mechanism and Graphic Registration of the Heart Beat, p. 135 et seq., 3rd ed., London, Shaw \& Sons, Ltd.

Myers, G. B., Klein, H. A., Stoffer, B. E. (1948). Amer. Heart J., 35, 1.

Schlesinger, P.; Beuchimol, A. B., and Cotrim, M. R. (1949). Ibid., 37, 1110.

Sodi-Pallares, D., Vizcaino, M., Soberon, J., and Cabrera, E. (1947). Ibid., 33, 819.

White, P. D., Smithwick, P. H., Mathews, M. W., and Evans, E. (1945). Ibid., 30, 165.

Wilson, F. N., Johnston, F. D., Rosenbaum, F. F., Erlanger, H., Kossmahn, C. E., Hecht, H., Cotrim, N., de Oliveira, R. M., Scarsi, R., and Barker, P. S. (1944). Ibid., 27, 19.

, Rosenbaum, F. F., and Johnston, F. D. (1947). Advances in Internal Medicine, Vol. II, p. 39. New York, Inter-science Publishers, Inc.

Wood, P. (1948). Brit. Heart J., 10, 87.

-

Zuckermann, R., Cabrera, E., Fishleder, B. L., and Sodi-Pallares, D. (1948). Amer. Heart J., 35, 421. 